\title{
Downlink Signal Measurement Algorithm for WCDMA/HSPA/HSPA+
}

\author{
Bit-Na Kwon ${ }^{1}$, Eui-Hak Lee ${ }^{1}$, Dae-Ki Hong ${ }^{2}$, Sung-Jin Kang ${ }^{3}$, Min-Goo Kang ${ }^{4}$ \\ and Hyoung-Kyu Song ${ }^{1}$ \\ ${ }^{1}$ uT Communication Research Institute, Sejong University \\ Seoul, South Korea \\ ${ }^{2}$ Department of Information \& Communication Engineering, Sangmyung University \\ Cheonan, South Korea \\ ${ }^{3}$ Department of EEC Engineering, Korea University of Technology and Education \\ Cheonan, South Korea \\ ${ }^{4}$ Department of Information and Telecommunication, Hanshin University \\ Osansi, South Korea \\ [e-mail: songhk@ sejong.ac.kr] \\ *Corresponding author: Hyoung-Kyu Song
}

Received March 3, 2015; revised June 30, 2015; accepted July 29, 2015; published August 31, 2015

\begin{abstract}
Wideband code division multiple access (WCDMA), high speed packet access (HSPA) and HSPA+ are third generation partnership project (3GPP) standards. These systems are the major wireless communication standards. In order to test the performance of WCDMA/HSPA/HSPA+ signal in a base station, the measurement hardware is required to the evaluation of the transmitted signals. In this paper, the algorithm for the performance measurement of the WCDMA/HSPA/HSPA+ is proposed. Also, the performance of the measurement algorithm is used to evaluate the generated signal by the WCDMA/HSPA/HSPA+ signal generator. Generally, the algorithm of normal modems cannot be applied to the measurement system because the signal measurement equipment needs to guarantee the high accuracy. So, the WCDMA/HSPA/HSPA+ signal measurement algorithm for the accurate measurement is proposed. By the simulation, it is confirmed that the proposed measurement algorithm has good performance compared with the specification. Therefore, the proposed algorithm can be usefully applied to verify the performance of the measurement using the simulation.
\end{abstract}

Keywords: WCDMA, HSPA, HSPA+, downlink, 3GPP, measurement algorithm

A preliminary version of this paper was presented at ICONI 2014, and was selected as an outstanding paper. This work was supported by the ICT R\&D program of MSIP/IITP, Republic of Korea [14-911-01-003, SW definable T\&M equipment development for the advancement of radio base station inspection]. 


\section{Introduction}

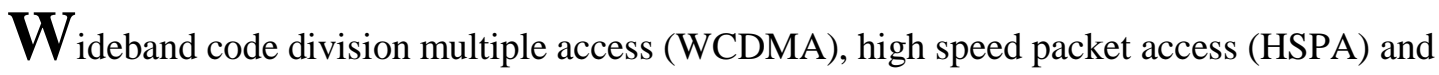
HSPA+ are third generation partnership project (3GPP) standards. WCDMA/HSPA/HSPA+ standard is widely used in wireless communication market [1].

In order to test the performance of the WCDMA/HSPA/HSPA+ system in a base station, the measurement hardware is required for the evaluation of the transmitted signal. The equipment measures the phase error, the magnitude error, the error vector magnitude (EVM) and so on for the multi-slot.

In this paper, the algorithm for the performance measurement of the WCDMA/HSPA/HSPA+ is proposed and implemented by simulation. Also, the performance of the measurement algorithm is used to evaluate the generated signal by the WCDMA/HSPA/HSPA+ signal generator.

Generally, the algorithm of normal modems cannot be applied to the measurement system because the signal measurement equipment needs to guarantee the high accuracy. Therefore, the WCDMA/HSPA/HSPA+ signal measurement algorithm for the accurate measurement is proposed in this paper. The proposed algorithm uses the parameter estimation method in Section 3. The accuracy of the measurement is improved by the interpolation.

\section{WCDMA/HSPA/HSPA+ System Overview}

\subsection{General Characteristics}

The general characteristics of WCDMA/HSPA/HSPA+ are represented as follows,

- Chip rate: 3.84 Mcps

- Frame structure: 2560 chips $/$ slot $^{\times} 15$ slots $=10 \mathrm{~ms}$.

The constellations of WCDMA/HSPA/HSPA+ are represented variously since the modulation is occurred in each channel and the modulated signals are combined. Orthogonal variable spreading factor (OVSF) is used for the division of the channel and gold code is used for the division of the terminal of the cell [2].

\subsection{Downlink Physical Channel}

In WCDMA/HSPA/HSPA+, 15 slots per frame are included and 2560 chips per slot are allocated. So, the number of chips is 38400 in the one frame. In some cases, the frame is classified to the sub-frame and the sub-frame is composed of 3 slots (7680 chips). 


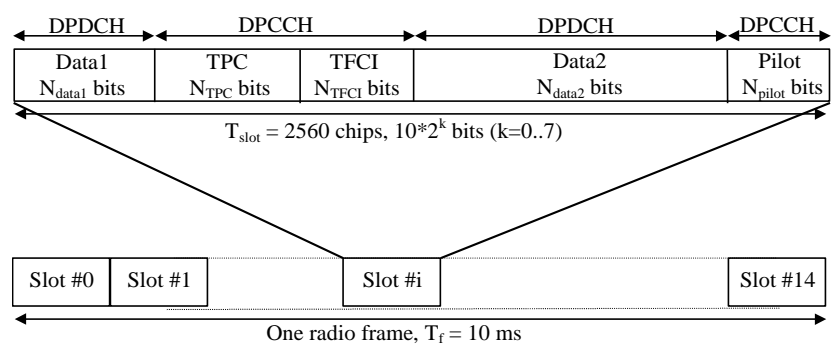

Fig. 1. DPCH frame format.

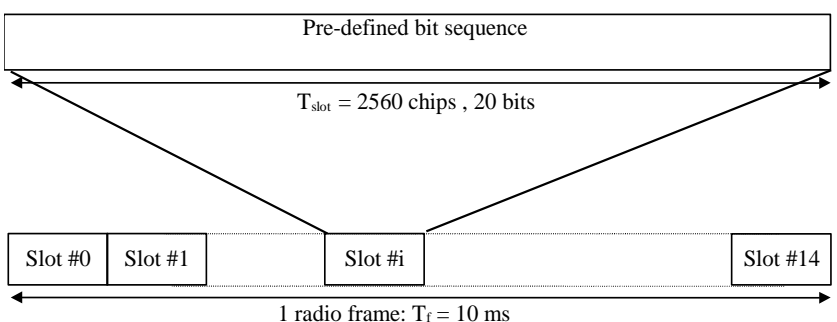

Fig. 2. CPICH frame format.

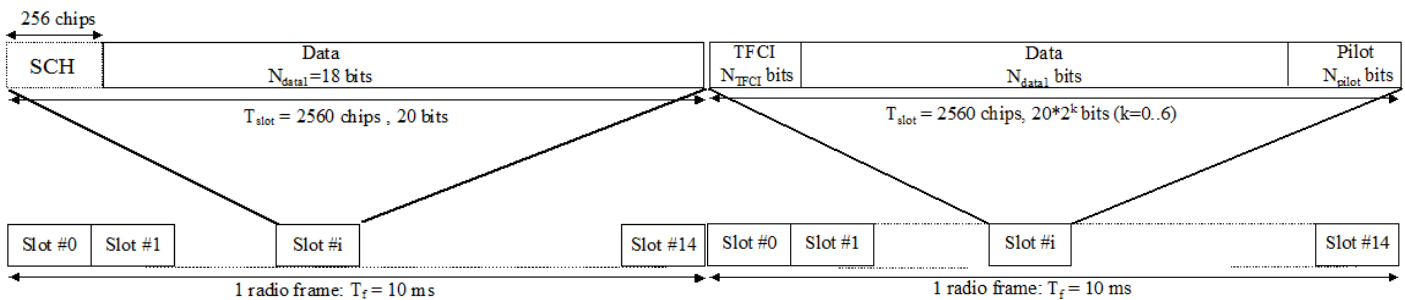

(a) $\mathrm{P}-\mathrm{CCPCH}$ and $\mathrm{SCH}$.

(b) $\mathrm{S}-\mathrm{CCPCH}$

Fig. 3. P-CCPCH and S-CCPCH frame format.

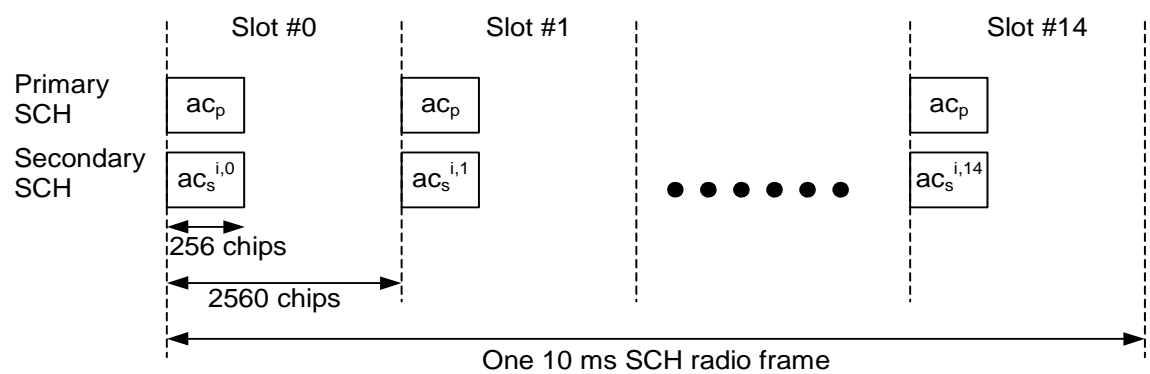

Fig. 4. $\mathrm{P}-\mathrm{SCH}$ and $\mathrm{S}-\mathrm{SCH}$ frame format. 


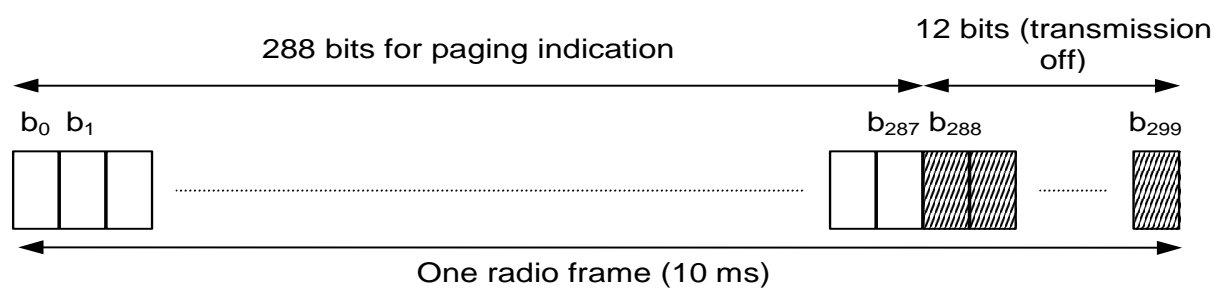

Fig. 5. PICH frame format.

Common pilot channel (CPICH), common control physical channel (CCPCH), synchronization channel $(\mathrm{SCH})$, paging indicator channel $(\mathrm{PICH})$ and dedicated physical channel (DPCH) are downlink channels for WCDMA, HSPA and HSPA+. Additionally, high speed shared control channel(HS-SCCH) and HS-physical downlink shared channel (HS-PDSCH) are used as the base station downlink channels for HSPA and HSPA+ [3].

Fig. 1-6 show the frame formats of the downlink physical channels. DPCH in Fig. 1 transmits the data information and consists of dedicated physical data channel (DPDCH) and dedicated physical control channel (DPCCH). The parameter k in Fig. 1 is the total number of bits per downlink DPCH slot and it is related to the spreading factor (SF) as $\mathrm{SF}=512 / 2^{\mathrm{k}}$. The exact number of the downlink DPCH fields $\left(\mathrm{N}_{\text {pilot }}, \mathrm{N}_{\mathrm{TPC}}, \mathrm{N}_{\mathrm{TFCI}}, \mathrm{N}_{\mathrm{data} 1}\right.$ and $\mathrm{N}_{\text {data2 }}$ ) is given in [3]. CPICH is one of the downlink physical channels and is composed as Fig. 2. CPICH transmits the pilot bits that the transmitter and the receiver are already known each other. In this paper, the pilot information of $\mathrm{CPICH}$ is used for the measurement and the synchronization. Fig. 3 shows the structure of $\mathrm{CCPCH}$. The primary-CCPCH $(\mathrm{P}-\mathrm{CCPCH})$ in Fig. 3(a) is used to carry the broadcast channel $(\mathrm{BCH})$ transport channel. Also, the P-CCPCH is not transmitted during the first 256 chips. Instead, $\mathrm{SCH}$ is transmitted during the first 256 chips like Fig. 3(a). The secondary-CCPCH $(\mathrm{S}-\mathrm{CCPCH})$ in Fig. 3(b) is used to carry the forward access channel (FACH) and paging channel (PCH). S-CCPCH has two types that include transport format combination indicator (TFCI) and do not include TFCI. SCH is used for the cell search and consists of primary-SCH (P-SCH) and secondary-SCH (S-SCH) like Fig. 4. During the $10 \mathrm{~ms}$ radio frames, the $\mathrm{P}-\mathrm{SCH}$ and $\mathrm{S}-\mathrm{SCH}$ are divided to 15 slots and each length is 2560 chips. In P-SCH, the primary synchronization code (PSC) $c_{p}$ is transmitted in each slot. In S-SCH, the secondary synchronization code (SSC) $\mathrm{c}_{\mathrm{s}}^{\mathrm{i}, \mathrm{k}}$ is transmitted in each slot where $\mathrm{k}=0,1, \ldots, 14$ is the slot number and $\mathrm{i}=0,1, \ldots, 63$ is the number of the scrambling code group. The PSC and SSC are modulated by the symbol. The symbol means the presence/absence of space time transmit diversity (STTD) encoding on the P-CCPCH. PICH in Fig. 5 is used to carry the paging indicators. One PICH frame consists of 300 bits $\left(b_{0}, b_{1}, \ldots\right.$, $\mathrm{b}_{299}$ ). The first 288 bits are used to carry the paging indicators and the remaining 12 bits are not formally part of the PICH and are not transmitted.

HS-SCCH and HS-PDSCH are the physical channels used in only HSPA/HSPA+ while other channels are used in the all systems of WCDMA, HSPA and HSPA+. The frame format of HS-SCCH is represented in Fig. 6. The HS-SCCH has a fixed rate of $60 \mathrm{kbps}$ since the OVSF spreading factor of HS-SCCH is fixed to 128 and is used to carry downlink signaling related to HS-downlink shared channel (HS-DSCH). Fig. 7 shows the frame format of HS-PDSCH used to carry the HS-DSCH. The OVSF spreading factor of HS-PDSCH is fixed to 16 and quadrature phase shift keying (QPSK), 16 quadrature amplitude modulation (QAM) and 64 QAM are used as the modulation scheme. 


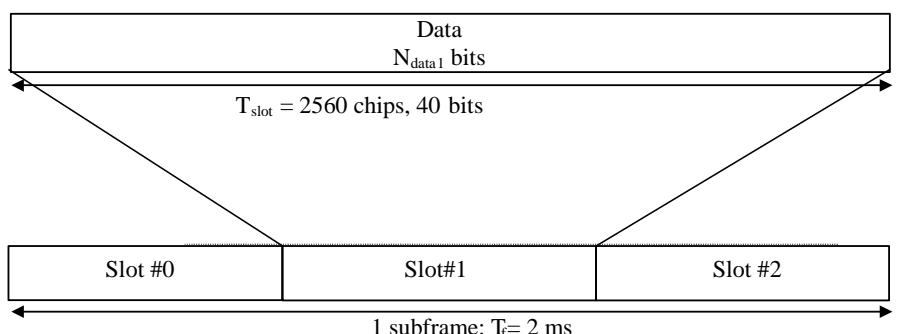

Fig. 6. HS-SCCH frame format.

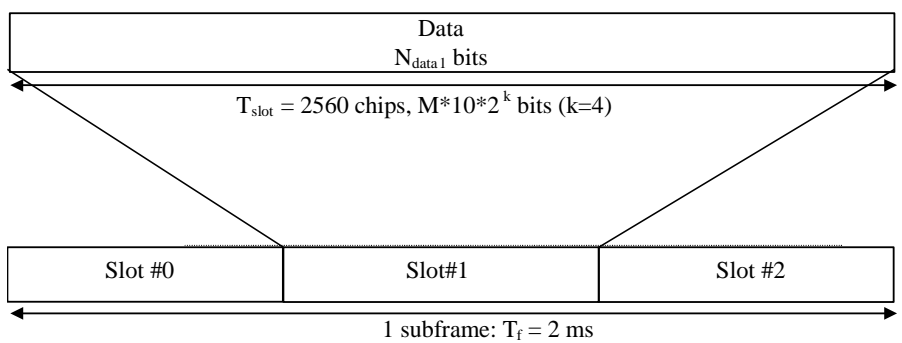

Fig. 7. HS-PDSCH frame format.

\subsection{Spreading and Modulation}

The division of downlink channel is conducted by OVSF codes and the division of cell is conducted by long scrambling codes. The combination of channels is not limited when the orthogonality of OVSF is guaranteed. The channels except SCH are spread by each OVSF code for the channel distinction.

Table 1. Modulation method according to the channel.

\begin{tabular}{|l|c|}
\hline Physical channel & IQ mapping \\
\hline HS-PDSCH, & $\begin{array}{c}\text { QPSK, 16QAM or 64 } \\
\text { S-CCPCH }\end{array}$ \\
\hline $\begin{array}{l}\text { All other channels } \\
\text { (except the SCH) }\end{array}$ & QAM \\
\hline
\end{tabular}

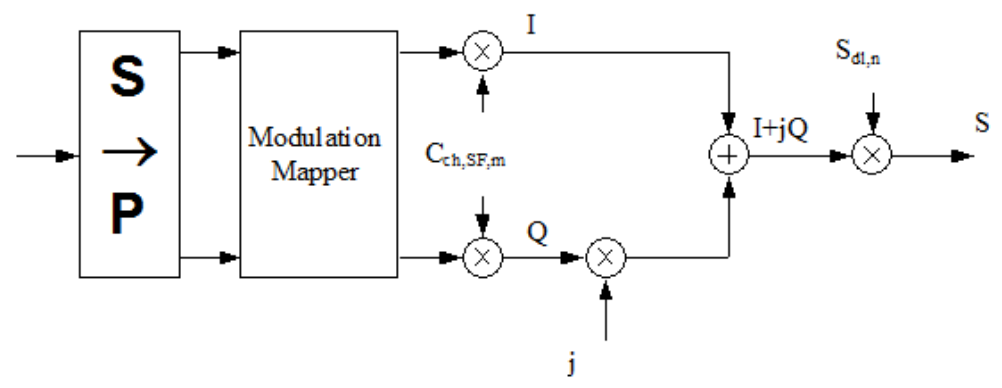

Fig. 8. Spreading process in downlink. 


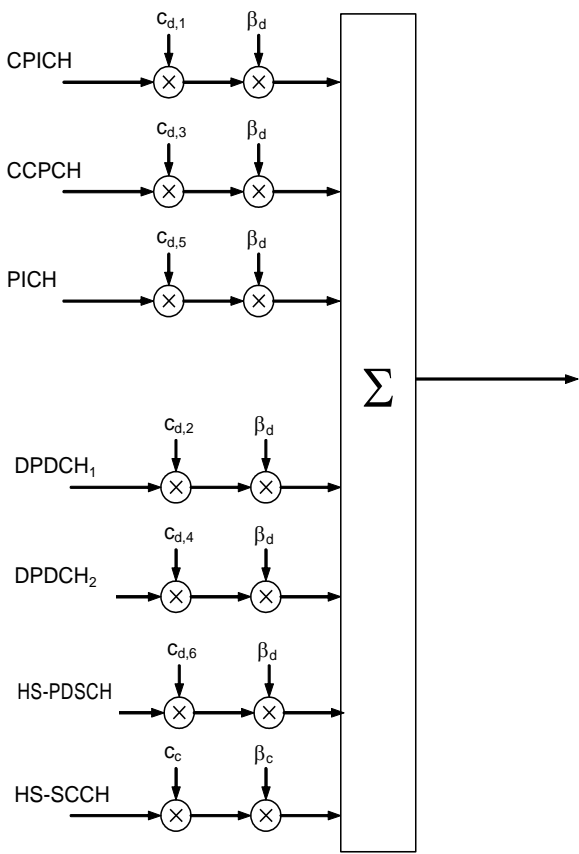

Fig. 9. Modulation and spreading for each downlink physical channel.

The modulation scheme of each channel is shown in Table 1. All channels are basically modulated by QPSK but 16 QAM and 64 QAM are used according to the channel. The channels are mapped to in-phase (I) branch and quadrature-phase (Q) branch and are added as Fig. 8. Fig. 8 shows the spreading process for all physical channels except SCH. After the channels are mapped to I and Q by the modulation mapper, the spreading operation is occurred. Since the modulated channels are added like Fig. 9 after each gain is multiplied to the channels, the constellations are represented variously.

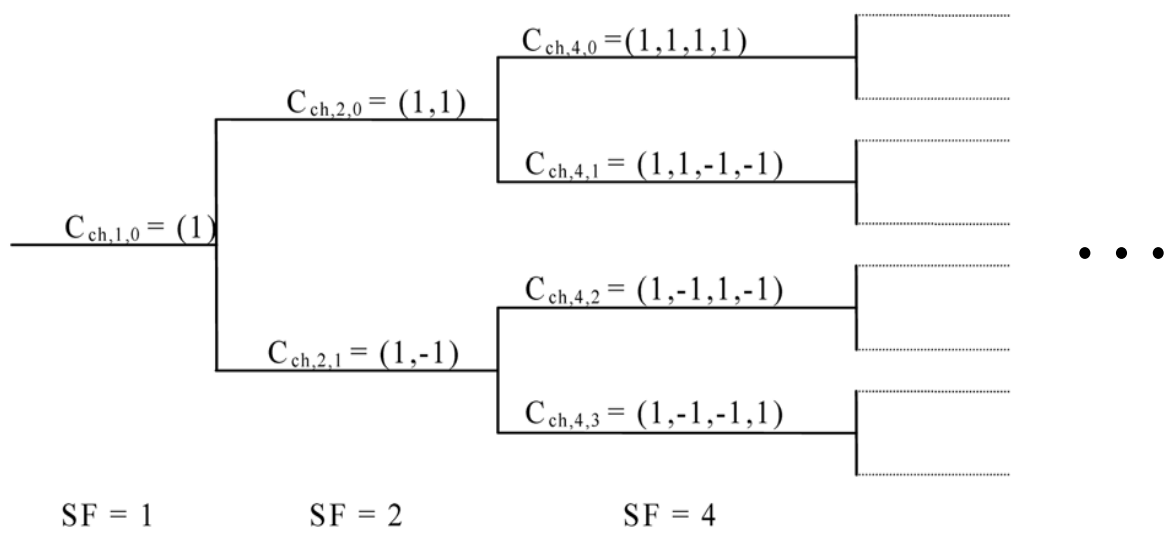

Fig. 10. OVSF code generator. 


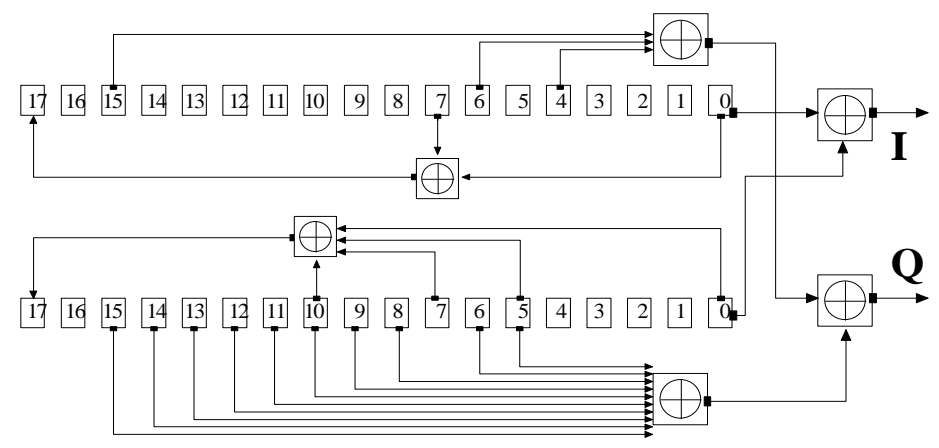

Fig. 11. Scrambling code generator.

OVSF for the division of downlink channel is generated by Hadamard matrix and it is represented in Fig. 10. The first code of SF 256 is allocated to CPICH and other codes are randomly allocated to other channels. The scrambling code for the distinction of the base station is generated as Fig. 11 and the detailed process for the code generation is explained in [4].

Also, the root raised cosine filter having 0.22 roll-off factor is used as the pulse shaping filter in the downlink.

\section{Proposed Measurement Algorithm for WCDMA/HSPA/HSPA+}

In this paper, the algorithm measuring the signals of WCDMA/HSPA/HSPA+ base stations is proposed and Fig. 12 shows the block diagram of the proposed measurement algorithm.

In the downlink, test model 1, 2, 3, 4, 5 and 6 are used for the measurement of WCDMA, HSPA and HSPA+ [5]. Each test model is composed as Table 2, 3 and $\mathbf{4}$. The test model 1, 2, 3 and 4 are applied to the measurement of WCDMA signals, the test model 5 is applied to the measurement of HSPA signals and the test model 6 is applied to the measurement of HSPA+ signals.

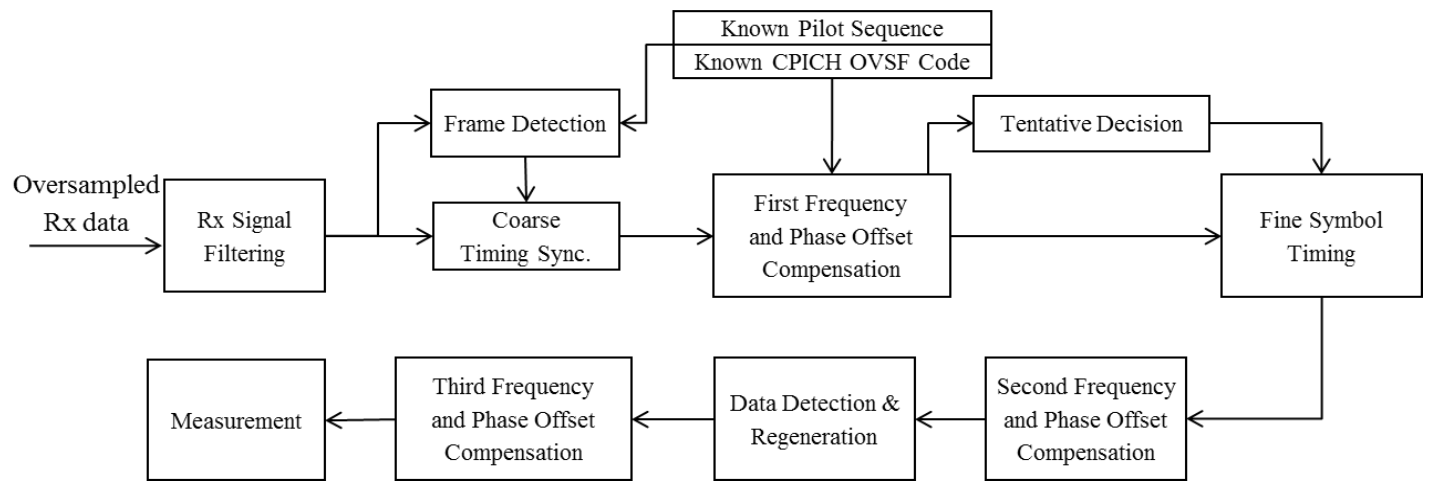

Fig. 12. Measurement algorithm for WCDMA/HSPA/HSPA+. 
Table 2. Test model 1, 2, 3 and 4 for WCDMA.

(a) Test model 1

\begin{tabular}{|c|c|c|c|c|c|}
\hline Type & $\begin{array}{c}\text { Number of } \\
\text { Channels }\end{array}$ & $\begin{array}{c}\text { Fraction of } \\
\text { Power }(\%)\end{array}$ & $\begin{array}{c}\text { Level setting } \\
(\mathrm{dB})\end{array}$ & $\begin{array}{c}\text { Channelization } \\
\text { Code }\end{array}$ & $\begin{array}{c}\text { Timing offset } \\
\left(\mathrm{x} 256 \mathrm{~T}_{\text {chip }}\right)\end{array}$ \\
\hline P-CCPCH+SCH & 1 & 10 & -10 & 1 & 0 \\
\hline Primary CPICH & 1 & 10 & -10 & 0 & 0 \\
\hline PICH & 1 & 1.6 & -18 & 16 & 120 \\
\hline $\begin{array}{c}\text { S-CCPCH containin } \\
\text { g PCH (SF }=256)\end{array}$ & 1 & 1.6 & -18 & 3 & 0 \\
\hline $\begin{array}{c}\text { DPCH } \\
(\mathrm{SF}=128)\end{array}$ & $\begin{array}{c}4^{*} / 8^{* / 16 / 32} \\
/ 64\end{array}$ & 76.8 in total & & & \\
\hline Note *: Only applicable to Home BS
\end{tabular}

(b) Test model 2

\begin{tabular}{|c|c|c|c|c|c|}
\hline Type & $\begin{array}{l}\text { Number of } \\
\text { Channels }\end{array}$ & $\begin{array}{l}\text { Fraction of } \\
\text { Power (\%) }\end{array}$ & $\begin{array}{l}\text { Level setting } \\
(\mathrm{dB})\end{array}$ & $\begin{array}{c}\text { Channelization } \\
\text { Code }\end{array}$ & $\begin{array}{l}\text { Timing offset } \\
\left(\mathrm{x} 256 \mathrm{~T}_{\text {chip }}\right)\end{array}$ \\
\hline $\mathrm{P}-\mathrm{CCPCH}+\mathrm{SCH}$ & 1 & 10 & -10 & 1 & 0 \\
\hline Primary $\mathrm{CPICH}$ & 1 & 10 & -10 & 0 & 0 \\
\hline $\mathrm{PICH}$ & 1 & 1.6 & -18 & 16 & 120 \\
\hline $\begin{array}{l}\text { S-CCPCH containin } \\
\text { g PCH }(\mathrm{SF}=256)\end{array}$ & 1 & 1.6 & -18 & 3 & 0 \\
\hline $\begin{array}{c}\mathrm{DPCH} \\
(\mathrm{SF}=128)\end{array}$ & $\begin{array}{c}4 * / 8 * / 16 / 32 \\
/ 64 \\
\end{array}$ & 76.8 in total & & & \\
\hline
\end{tabular}

(c) Test model 3

\begin{tabular}{|c|c|c|c|c|c|}
\hline Type & $\begin{array}{l}\text { Number of } \\
\text { Channels }\end{array}$ & $\begin{array}{l}\text { Fraction of } \\
\text { Power (\%) } \\
4 * / 8 * / 16 / 32\end{array}$ & $\begin{array}{c}\text { Level settings } \\
(\mathrm{dB}) \\
4 * / 8 * / 16 / 32\end{array}$ & $\begin{array}{c}\text { Channelization } \\
\text { Code }\end{array}$ & $\begin{array}{l}\text { Timing offset } \\
\left(\mathrm{x} 256 \mathrm{~T}_{\text {chip }}\right)\end{array}$ \\
\hline $\mathrm{P}-\mathrm{CCPCH}+\mathrm{SCH}$ & 1 & $\begin{array}{c}15,8 / 15,8 / 12 \\
6 / 7,9\end{array}$ & $-8 /-8 /-9 /-11$ & 1 & 0 \\
\hline Primary $\mathrm{CPICH}$ & 1 & $\begin{array}{c}15.8 / 15.8 / 12 \\
6 / 7,9 \\
\end{array}$ & $-8 /-8 /-9 /-11$ & 0 & 0 \\
\hline $\mathrm{PICH}$ & 1 & $2.5 / 2.5 / 5 / 1.6$ & $-16 /-16 /-13 /-18$ & 16 & 120 \\
\hline $\begin{array}{l}\text { S-CCPCH containin } \\
\text { g PCH }(\mathrm{SF}=256)\end{array}$ & 1 & $2.5 / 2.5 / 5 / 1.6$ & $-16 /-16 /-13 /-18$ & 3 & 0 \\
\hline $\begin{array}{c}\mathrm{DPCH} \\
(\mathrm{SF}=256)\end{array}$ & $4 * / 8 * / 16 / 32$ & $\begin{array}{l}\text { 63,4/63,4/63, } \\
7 / 80,4 \text { in total } \\
\end{array}$ & & & \\
\hline
\end{tabular}

(d) Test model 4

\begin{tabular}{|c|c|c|c|c|c|}
\hline Type & $\begin{array}{c}\text { Number of C } \\
\text { hannels }\end{array}$ & $\begin{array}{c}\text { Fraction of } \\
\text { Power }(\%)\end{array}$ & $\begin{array}{c}\text { Level setting } \\
(\mathrm{dB})\end{array}$ & $\begin{array}{c}\text { Channelization } \\
\text { Code }\end{array}$ & Timing offset \\
\hline $\begin{array}{c}\text { P-CCPCH+SCH w } \\
\text { hen Primary CPIC } \\
\text { H is disabled }\end{array}$ & 1 & $100 \cdot 10^{\frac{-x}{10}}$ & $-\mathrm{X}$ & 1 & 0 \\
\hline $\begin{array}{c}\text { P-CCPCH+SCH w } \\
\text { hen Primary CPIC } \\
\text { H is enabled }\end{array}$ & 1 & $100 \cdot 10^{\frac{-x-3}{10}}$ & $-\mathrm{X}-3$ & 1 & 0 \\
\hline \multicolumn{7}{|l|}{ Primary CPICH } & 1 & $100 \cdot 10 \frac{-x-3}{10}$ & $-\mathrm{X}-3$ & 0 & 0 \\
\hline
\end{tabular}


Table 3. Test model 5 for HSPA.

\begin{tabular}{|c|c|c|c|c|c|}
\hline Type & $\begin{array}{l}\text { Number of } \\
\text { Channels }\end{array}$ & $\begin{array}{l}\text { Fraction of } \\
\text { Power (\%) }\end{array}$ & $\begin{array}{l}\text { Level setting } \\
\text { (dB) }\end{array}$ & $\begin{array}{l}\text { Channelization } \\
\text { Code }\end{array}$ & $\begin{array}{l}\text { Timing offset } \\
\left(\mathrm{x} 256 \mathrm{~T}_{\text {chin }}\right)\end{array}$ \\
\hline $\mathrm{P}-\mathrm{CCPCH}+\mathrm{SCH}$ & 1 & 7.9 & -11 & 1 & 0 \\
\hline Primary CPICH & 1 & $\underline{7.9}$ & -11 & 0 & 0 \\
\hline $\mathrm{PICH}$ & 1 & 1.3 & -19 & 16 & 120 \\
\hline $\begin{array}{l}\text { S-CCPCH containin } \\
\text { g PCH }(\mathrm{SF}=256)\end{array}$ & 1 & 1.3 & -19 & 3 & 0 \\
\hline $\begin{array}{c}\mathrm{DPCH} \\
(\mathrm{SF}=128)\end{array}$ & $30 / 14 / 6 / 4(*)$ & $\begin{array}{l}14 / 14.2 / 14.4 / \\
14.2 \text { in total }\end{array}$ & & & \\
\hline HS-SCCH & 2 & 4 in total & & & \\
\hline $\begin{array}{c}\text { HS-PDSCH (16QA } \\
\mathrm{M}) \\
\end{array}$ & $8 / 4 / 2\left(^{*}\right)$ & $\begin{array}{c}63.6 / 63.4 / 63 . \\
2 \text { in total }\end{array}$ & & & \\
\hline
\end{tabular}

Table 4. Test model 6 for HSPA+.

\begin{tabular}{|c|c|c|c|c|c|}
\hline Type & $\begin{array}{c}\text { Number of } \\
\text { Channels }\end{array}$ & $\begin{array}{l}\text { Fraction of } \\
\text { Power (\%) }\end{array}$ & $\begin{array}{c}\text { Level setting (d } \\
\mathrm{B})\end{array}$ & $\begin{array}{c}\text { Channelization } \\
\text { Code }\end{array}$ & $\begin{array}{l}\text { Timing offset } \\
\left(\mathrm{x} 256 \mathrm{~T}_{\text {chip }}\right)\end{array}$ \\
\hline $\mathrm{P}-\mathrm{CCPCH}+\mathrm{SCH}$ & 1 & 7.9 & -11 & 1 & 0 \\
\hline Primary $\mathrm{CPICH}$ & 1 & 7.9 & -11 & 0 & 0 \\
\hline $\mathrm{PICH}$ & 1 & 1.3 & -19 & 16 & 120 \\
\hline $\begin{array}{c}\text { S-CCPCH containin } \\
\text { g PCH }(\mathrm{SF}=256)\end{array}$ & 1 & 1.3 & -19 & 3 & 0 \\
\hline $\begin{array}{c}\mathrm{DPCH} \\
(\mathrm{SF}=128) \\
\end{array}$ & $30 / 4 *$ & 27.1 in total & & & \\
\hline HS-SCCH & 2 & 4 in total & & & \\
\hline $\begin{array}{c}\text { HS-PDSCH (64QA } \\
\mathrm{M})\end{array}$ & $8 / 4 *$ & 50.5 in total & & & \\
\hline \multicolumn{6}{|c|}{$\begin{array}{l}\text { Note *: } 8 \text { HS-PDSCH shall be taken together with } 30 \mathrm{DPCH} \text {, and (for Home BS only) } 4 \text { HS-PDSCH shal } \\
1 \text { be taken with } 4 \mathrm{DPCH} \text {. }\end{array}$} \\
\hline
\end{tabular}

\subsection{Received Signal Filtering}

In the receiver, the filtering for the received signal is conducted by the root raised cosine filter like the filter at the transmitter. As a result, the received signal without interference among symbols is generated.

\subsection{Frame Detection}

The measurement equipment detects the frame for the 8 times oversampled signal. The pilot information of CPICH is used because the receiver already knows the bit sequence of CPICH and the OVSF code of CPICH is always same. The equipment calculates the correlation of the received signal and the prescribed 2560 chips, and then the frame is detected by the peak value of the correlation.

\subsection{First Frequency Offset and Carrier Phase Compensation}

After the frame detection, the frequency offset and the carrier phase are estimated for the accurate data demodulation and the 20 bits of the first slot are used. In this paper, the maximum likelihood (ML) algorithm is used for the frequency offset estimation [6]. After the compensation of signal by ML, the carrier phase is estimated and compensated by the ratio between I and Q component. 


\subsection{Tentative Decision}

Following process is progressed as the unit of a slot. All channels are detected by the OVSF code. All 20 bits of CPICH are detected and the detected bits are used as the reference bits when the parameter of all channels is estimated.

\subsection{Fine Symbol Timing}

For the WCDMA/HSPA/HSPA+ signal measurement, the fine symbol timing is additionally estimated since the fine error strongly influences on the measurement. In this paper, the interpolation is used to obtain the exact symbol timing. And the fine symbol timing is obtained by the correlation between the interpolated reception signal and the $\mathrm{CPICH}$ chip spreaded by OVSF.

\subsection{Second and Third Frequency Offset/Carrier Phase Compensation}

The second frequency offset/carrier phase and third frequency offset/carrier phase are estimated by using the received signal after fine symbol timing. Since the measurement is strongly influenced by the small estimation error compared with the normal modems, the additional frequency offset/carrier phase compensation is conducted. The channel estimation is performed for the CPICH bits of all slots. The algorithm is equal to the algorithm of Section 3.3. For the accurate measurement, the channel estimation is repeatedly performed in consideration of the complexity for the system [7].

\subsection{Data Estimation and Signal Regeneration}

According to test model 5 and 6, the channels are composed and each data is detected as Section 3.3. The detected data enters into the signal regenerator and the reference signal is generated.

The reference and test signal that the frequency and phase are compensated are used to perform the measurement of the various signals.

\subsection{Parameter Measurement}

In WCDMA/HSPA/HSPA+, the parameter measurement is performed by the difference between the reference signal $\left(r_{\text {ref }}\right)$ and the test signal $\left(r_{\text {test }}\right)$. The reference signal means the generated signal by the receiver without the error and the test signal means the estimated signal after the transmission in practice.

One of the measurement parameters is $\rho$ (rho) meaning the ratio between the total power of the received signal and the correlation power. The system has good performance when the value of $\rho$ is close to 1 and $\rho$ can be represented as follows,

$$
\rho=\frac{\text { signal power }}{\text { signal power + error power }}=\frac{\left|\operatorname{Cor}\left(r_{\text {ref }}, r_{\text {test }}\right)\right|^{2}}{\left|r_{\text {ref }}\right|^{2} \times\left|r_{\text {test }}\right|^{2}} \text {. }
$$

$\operatorname{EVM}(\%)$ meanging error vector magnitude is expressed as follows,

$$
\operatorname{EVM}=\frac{r m s\left(r_{\text {test }}-r_{r e f}\right)}{r m s\left(r_{r e f}\right)} \times 100 \%
$$

Also, phase error and frequency error are the important measurement parameters. If the phase error is high, it means that the practical circuit has some problems and the performance 
of the detection at the receiver is degraded. The frequency error evaluates the performance of frequency synthesizer and phase locked loop. If the frequency error is high, it means that the frequency conversion is slow and the interference by the frequncy error is occurred at the receiver.

Additionally, the important parameters are code domain power (CDP), constellation, total power and I/Q origin offset.

\section{Simulation Results}

For the evaluation of the proposed measurement algorithm, the received signal is compared with the transmitted signal. Using the conventional signal generator, the 8 times oversampled signal is obtained after the WCDMA/HSPA/HSPA+ radio-frequency (RF) signals are generated for WCDMA/HSPA/HSPA+ system and converted to the baseband signal. The major factors to determine the complexity of the measurement algorithm are oversampling rate and interpolation. If the oversampling and interpolation are performed so many times, the complexity is very high while the performance is improved. The proposed measurement algorithm maintains the reasonable complexity since the sufficient performance is obtained by using only 8 times oversampling and 20 times interpolation. For the accurate comparison, the proposed algorithm is compared with the standard performance of specification.

\subsection{Simulation Result for WCDMA}

Table 5. Parameter measurement for the WCDMA signal.

\begin{tabular}{|c|c|c|}
\hline Parameter & Specification & Proposed Algorithm \\
\hline Total Power & & $-27.60 \mathrm{~dB}$ \\
\hline Rho & & 0.99995 \\
\hline rms EVM & $12.5 \%$ & $0.70 \%$ \\
\hline Peak EVM & & $2.09 \%$ \\
\hline Peak CDE & $-33 \mathrm{~dB}$ & $-62.52 \mathrm{~dB}$ \\
\hline Peak active CDE & & $-58.71 \mathrm{~dB}$ \\
\hline Relative CDE & $-21 \mathrm{~dB}$ & $-58.71 \mathrm{~dB}$ \\
\hline Magnitude Error & & $0.61 \%$ \\
\hline Phase Error & & $0.70^{\circ}$ \\
\hline Frequency Error & $\pm 15 \mathrm{MHz}$ & $19.71 \mathrm{~Hz}$ \\
\hline I/Q Origin Offset & $-17 \mathrm{~dB}$ & $-68.65 \mathrm{~dB}$ \\
\hline
\end{tabular}

Table 5 shows the simulation result for WCDMA RF signal. For this simulation, the test model 1 is used and the number of DPCHs is 4. It is confirmed that the algorithm for WCDMA is sufficiently satisfied with the specification. The proposed algorithm has good performance since the value of $\rho$ is high and the values of the phase and frequency error are small.

\subsection{Simulation Result for HSPA}

Table 6 shows the simulation result for HSPA RF signal. For the performance evaluation of the HSPA system, the test model 5 is used. The number of DPCHs is 4 and the number of 
HS-PDSCHs is 2. It is confirmed that the algorithm for HSPA is sufficiently satisfied with the specification. The proposed algorithm has good performance since the value of $\rho$ is high and the values of the phase and frequency error are small.

Table 6. Parameter measurement for the HSPA signal.

\begin{tabular}{|c|c|c|}
\hline Parameter & Specification & Proposed Algorithm \\
\hline Total Power & & $-27.75 \mathrm{~dB}$ \\
\hline Rho & & 0.99995 \\
\hline rms EVM & $12.5 \%$ & $0.73 \%$ \\
\hline Peak EVM & & $2.22 \%$ \\
\hline Peak CDE & $-33 \mathrm{~dB}$ & $-60.88 \mathrm{~dB}$ \\
\hline Peak active CDE & & $-51.10 \mathrm{~dB}$ \\
\hline Relative CDE & $-21 \mathrm{~dB}$ & $-51.10 \mathrm{~dB}$ \\
\hline Magnitude Error & & $0.64 \%$ \\
\hline Phase Error & & $0.79^{\circ}$ \\
\hline Frequency Error & $\pm 15 \mathrm{MHz}$ & $20.09 \mathrm{~Hz}$ \\
\hline I/Q Origin Offset & $-17 \mathrm{~dB}$ & $-69.76 \mathrm{~dB}$ \\
\hline
\end{tabular}

\subsection{Simulation Result for HSPA+}

Table 7. Parameter measurement for the HSPA+ signal.

\begin{tabular}{|c|c|c|}
\hline Parameter & Specification & Proposed Algorithm \\
\hline Total Power & & $-16.09 \mathrm{~dB}$ \\
\hline Rho & & 0.99996 \\
\hline rms EVM & $12.5 \%$ & $0.60 \%$ \\
\hline Peak EVM & & $1.65 \%$ \\
\hline Peak CDE & $-33 \mathrm{~dB}$ & $-61.67 \mathrm{~dB}$ \\
\hline Peak active CDE & & $-52.86 \mathrm{~dB}$ \\
\hline Relative CDE & $-21 \mathrm{~dB}$ & $-52.86 \mathrm{~dB}$ \\
\hline Magnitude Error & & $0.54 \%$ \\
\hline Phase Error & & $0.67^{\circ}$ \\
\hline Frequency Error & $\pm 15 \mathrm{MHz}$ & $7.55 \mathrm{~Hz}$ \\
\hline I/Q Origin Offset & $-17 \mathrm{~dB}$ & $-67.34 \mathrm{~dB}$ \\
\hline
\end{tabular}

Table 7 shows the simulation result for HSPA+ RF signal. In this simulation, the test model 6 for HSPA+ is used and the number of DPCHs and HS-PDSCHs is 4 respectively. It is confirmed that the algorithm for HSPA+ is sufficiently satisfied with the specification. The proposed algorithm has good performance since the value of $\rho$ is high and the values of the phase and frequency error are small.

\section{Conclusion}

One of the major mobile communication standards is a WCDMA system. The WCDMA system has been occupied to a large part of the mobile communication market and it has a 
number of commerialized base stations. Additionally, HSPA and HSPA+ are widely used for high speed data trasmission. In order to test the performance of WCDMA/HSPA/HSPA+ base stations, the measurement equipment is required to evaluate the transmitted signal at the WCDMA/HSPA/HSPA+ base stations.

In this paper, the algorithm measuring the performance of the base station is proposed for WCDMA/HSPA/HSPA+. Generally, the algorithm of normal modems cannot be applied to the measurement system since the fine error strongly influences on the measurement. Therefore, the parameter estimation method in Section 3 and the interpolation are used for the accurate measurement.

Through the simulation, it is confirmed that the proposed measurement algorithm has good performance compared with the specification. Therefore, the proposed algorithm can be usefully applied in order to verify the performance of the measurement using the simulation.

\section{References}

[1] L. Klozar, L. Polak, O. Kaller and J. Prokopec, "Effect of co-existence interferences on QoS of HSPA/WCDMA mobile networks," in Proc. of 23th Conference Radioelektronika, 2013. Article (CrossRef Link).

[2] 3GPP TS 25.201 V8.1.0, 3rd generation partnership project; Technical specification group radio access network; "Physical layer - general description (Release 8)", 2008.

[3] 3GPP TS 25.211 V8.4.0, 3rd generation partnership project; Technical specification group radio access network; "Physical channels and mapping of transport channels onto physical channels (FDD) (Release 8)," 2009.

[4] 3GPP TS 25.213 V8.4.0, 3rd generation partnership project; Technical specification group radio access network; "Spreading and modulation (FDD)," (Release 8), 2009.

[5] 3GPP TS 25.141 V8.6.0, 3rd generation partnership project; Technical specification group radio access network; "Base Station (BS) conformance testing (FDD)," (Release 8), 2009.

[6] U. Mengali and M. Morelli, "Data-aided frequency estimation for burst digital transmission," IEEE Trans. On Commun, vol. 45, no. 1, pp.23-25, 1997. Article (CrossRef Link).

[7] H.-Y. Jeong and H.-K. Song, "A reduced MIMO detector using post SNR ordering," IEICE Trans. Inf.\&Syst, vol. E96-D, no. 6, pp.1398-1401, 2013. Article (CrossRef Link)

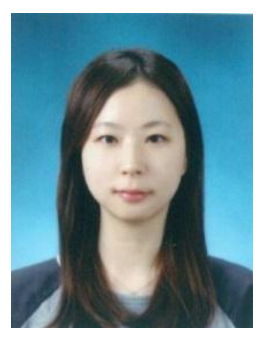

Bit-Na Kwon was born in 1990. She received a B.S. degree in Information \& Communication Engineering, Sejong University, Seoul, Korea, in 2014. She is working toward to M.S. degree in the Department of Information and Communications engineering, Sejong University, Seoul, Korea. Her research interests include WCDMA systems, wireless communication and cooperative communication.

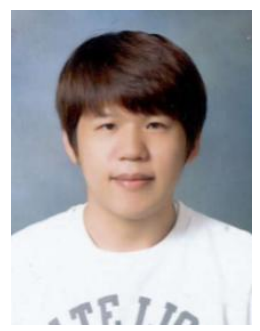

Eui-Hak Lee was born in 1989. He received a B.S. degree from Sejong University, Seoul, Korea, in 2012. He is currently with the Department of Information \& Communications Engineering, Sejong University, Seoul, Korea. His research interests include WCDMA systems, MIMO signal processing and cooperative communication. 


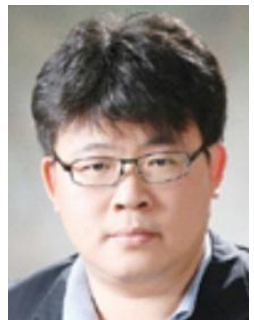

Dae-Ki Hong received a B.S. degree in computer engineering from Kwangwoon University, a M.S. degree in electronic engineering from Yonsei University and a Ph.D. degree in electrical and electronic engineering from Yonsei University, Seoul, Korea, in 1997 , 1999, and 2003, respectively. From 2003 to 2006 he had been a junior engineer in Korea Electronics Technology Institute (KETI), Korea. Since 2006, he has been a professor of the Department of Information \& Communication Engineering, Sangmyung University, Cheonan, Korea. His research interests include wireless and mobile communications, WPAN and WLAN.

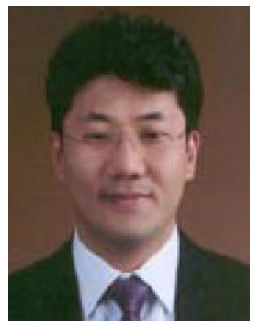

Sung-Jin Kang received B.S., M.S., and Ph.D. degrees in electronic engineering from Yonsei University, Seoul, Korea, in 1992, 1994, and 1998, respectively. From 2002 to 2007 he had been senior engineer in Korea Electronics Technology Institute (KETI), Korea. Since 2007, he has been a professor of the Department of EEC Engineering, Korea University of Technology and Education, Cheonan, Korea. His research interests include WPAN, WLAN and MODEM SoC.

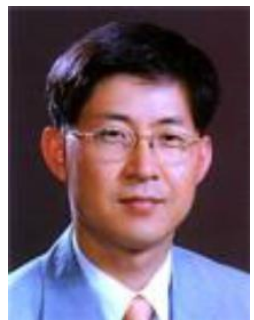

Min-Goo Kang received B.S., M.S., and Ph.D. degrees in electronic engineering from Yonsei University, Seoul, Korea, in 1986, 1989, and 1994, respectively. Since 2000, he has been a professor of the Department of Information and Telecommunication, Hanshin University, Osansi, Korea. His research interests include WPAN, WLAN and MODEM SoC.

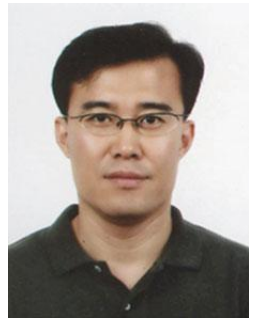

Hyoung-Kyu Song received B.S., M.S., and Ph.D. degrees in electronic engineering from Yonsei University, Seoul, Korea, in 1990, 1992, and 1996, respectively. From 1996 to 2000 he had been a managerial engineer in Korea Electronics Technology Institute (KETI), Korea. Since 2000, he has been a professor of the Department of Information and Communications Engineering, Sejong University, Seoul, Korea. His research interests include digital and data communications, information theory and their applications with an emphasis on mobile communications. 